\title{
POWERFUL WEBLOGS: DESIGN AND SEMIOTIC DESCRIPTION
}

\author{
Fahantidis NIKOS \\ University of Western Macedonia, New Technologies, Macedonia \\ nfaxanti@uowm.gr \\ Vamvakidou IFIGENEIAL \\ University of Western Macedonia, Greek Modern History and Culture, Macedonia \\ ibambak@uowm.gr \\ Traoudas ANTONIS \\ University of Western Macedonia, MA in Cultural Studies: Semiotic structures and practices, \\ Macedonia \\ antraoud@hotmail.com \\ Michailidis ILIAS \\ University of Western Macedonia, MA in Cultural Studies: Semiotic structures and practices, \\ Macedonia \\ elmicha217@gmail.com \\ Papoutzis LAZAROS \\ University of Western Macedonia, MA in Cultural Studies: Semiotic structures and practices, \\ Macedonia \\ sfinas3@gmail.com
}

\begin{abstract}
Blogs are a very important "tool" for professionals and individuals wishing to promote products, services, thoughts, ideas, news. It is one of the most important channels of communication which brings them into contact with a very important public figure, the internet. Creating a blog is not a simple process but a complex mixture of different points and signs. In the present work we make an effort to define well-known blogs using semiotics. Our research material consists of the 20 most visited blogs, according to the list appearing in the «Technorati» blog search tool. For the analysis of the visual material we use the Grammar of Visual Design by Kress G. \& Van Leeuwen T. (1996), a methodology based on the theory of Systemic Functional Grammar, which is the main subject of Halliday M. (1994). More specifically, in order to understand the power of weblogs, we are searching for: a) the mechanisms of organization and reconstruction of reality (representations), b) the production of meanings or even new ideologies by words and images (discourse) and c) the precise form and structure, signifiers and absences. It seems that web-blogs are creating a timeless space regulated by a nameless founder where the bits of information given although pointing to a specific date are part of a virtual non-time continuum.
\end{abstract}

Keywords: Internet, Blogs, Semiotics

\section{INTRODUCTION}

Blogs are a very important "tool" not only for professionals but also for individuals who wish to promote their products, services, thoughts, ideas and news. Blogs are one of the most important channels of communication that brings together a vast number of people, the users of internet (Drezner \& Farrell, 2007). The creation of a blog is not a simple process but a complex mixture of points and signs. Every blog is created in order for a certain goal to be achieved which in turns is determined by the needs of the developer/manufacturer (Mead, 2000). This goal, it is only accomplished when the massage, sought to be conveyed, is actually decoded and reaches its destination: "messages are always transmitted through a 
channel (Blood, 2000). The channel transmits the message from the sender to the receiver" (Gillian, 1982). Thus, referring to blogs, we consider a mechanical channel, that of the computer. More specifically, the message has as sender the owner of the blog and the aim is its design and constructs to attract the many users of the internet. The actual message is the realization of the blog while transmission happens through the use of computers and the Web (Blood, 2004). The receivers are the people who will visit the blog while the final destination of the message is the totality of internet users (Mishne, 2007).

\section{DEFINITIONS, STRUCTURE AND CHARACTERISTICS OF BLOGS}

Most of the blogs are interactive allowing visitors to add their comments or even to message each other. This is one of the critical characteristics that make blogs stand out of the rest static web pages. Many blogs provide with comments or news relevant to a specific topic while others function as online diaries and are more personal. Nevertheless, a typical blog combines text, images and links to other blogs, WebPages or media related to its focus (Lenhart \& Fox, 2006).

The average user of internet can easily and freely start its own blog through the utilization of applications, provided by different agents, which make its construction and design a very simple process. In return the providers of such applications have an automated advertisement to the blogs constructed. Most of the blogs are based on services like these. However, like any other webpage, the blogs too can be based in services where its administrator can have full control (Mishne, 2007).

A typical blog contains a title-logotype which is placed on the heading-upper section of the page, while often one or two linguistic, advertizing descriptions of it are following. The main part of the page is composed of two vertical columns with possible sub-columns, one for the presentation of the posts in a reverse timeline and another side column which contains links, posts archives, advertisements, and possibly interactive applications like polls, forms, and search engines (Mishne, 2007).

The footer contains information on the editor/sender, the Copyright, the privacy policy and the terms of use. Referring to the central column of posts, more frequently, is occupied by written text, archives, images, comments, videos and sound, links and guest books, which altogether construct a multimodal text (Mishne, 2007).

\section{METHODOLOGY}

\subsection{Method}

In order to analyze our data we used Semiotic analysis which is used for the study of informational systems and concepts since it deconstructs the ways in which meaning is produce (Barthes, 1957). As all semiotic systems, internet seems to be a grid of images, codes and symbols, each and every one in full dependence to each other. Although the internet is greatly depended on images, the idea of the "perfect language of images" cannot be realized even within this channel (Eco, 1997). The "pure iconicity" always fades when it comes to be depicted through a channel (screen, paper etc) (Sonesson, 2001). For the analysis of the visual material we use Kress \& van Leeuwen's "Grammar of Visual Design" (1996), a methodology based on the theory of Systemic Functional Grammar introduced by Halliday (1994).

According to Kress' visual analysis (1996: 120-130), for the western societies (reading from left to right) concerning how we absorb images-language-information, in the press spatial levels are chosen meaning the following: on the upper section of the page the utopian/unknown is revealed while on the lower section the steady /known. The elements on the center of the page consist of the core of the information given (Kress \& van Leeuwen, 1996: 119-158, Baldry \& Thibault 2006: 73-78, 94-97). 
The paradigmatic analysis refers to the vertical axis in which we can read the signifiers that have been chosen from the senders of weblogs while the syntagmatic analysis reveals the different combinations of these signifiers which construct the signified and the codes of the communication (Barthes, 1964). In the final step we try to apply the Greimas' square in order to find out the conceptual and visual codes that are dominant (Greimas, 1984).

\subsection{Research Questions}

In order to understand the role of blogs we consider:

a. The mechanisms of organization and reconstruction of reality (representations)

b. The production of meaning or even of new ideologies from the visual and linguistic discourse

c. The form and the structure, the signifiers and the absences

The process' stages of semiotic analysis are three:

We begin with the selection of the appropriate data.

We record and deconstruct in fragments the totality of blogs' elements. In this paper this second stage is covered by the extensive description of the blogs.

In the third stage a second degree analysis is following, in which the recorded elements of blogs are studied in terms of association with variables necessary for the decryption (social, political, economic, cultural criteria).

\subsection{Research Data}
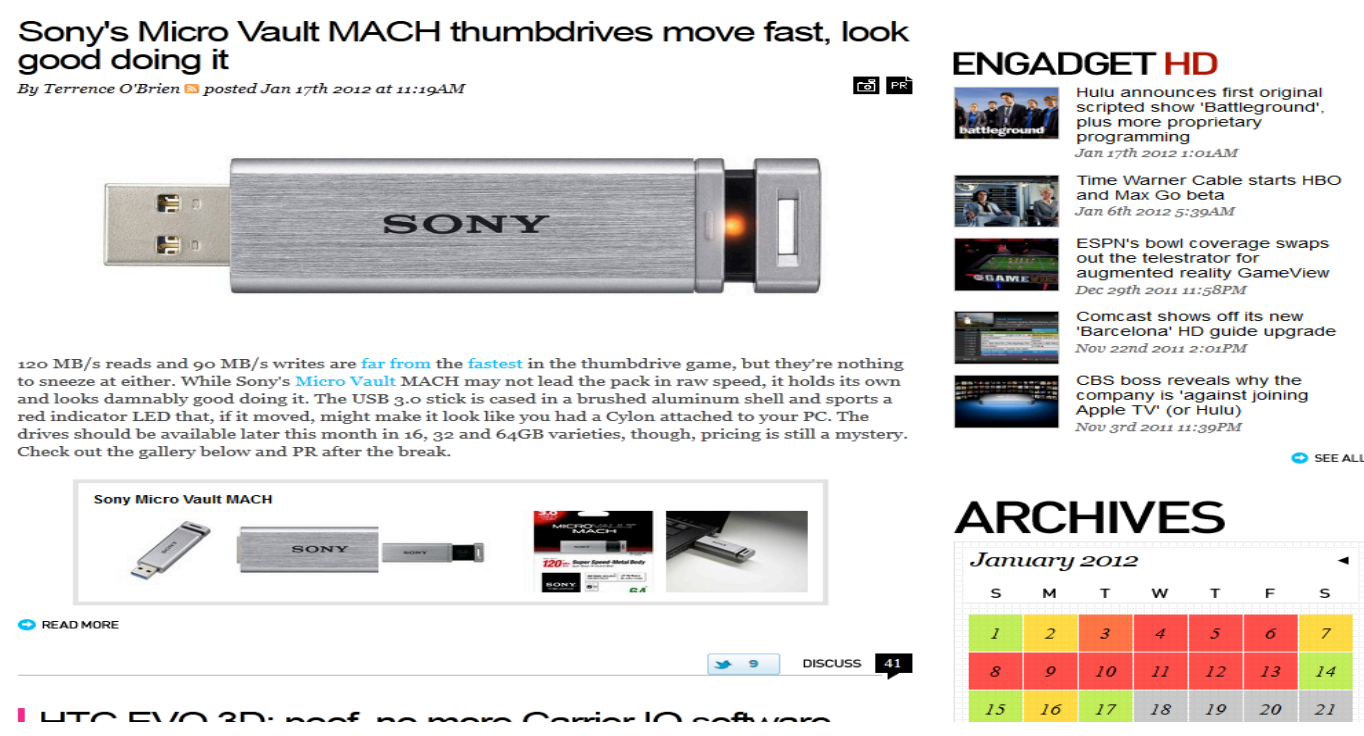

Figure 1. Engadget, main part

For the implementation of the research, 20 popular blogs were chosen. These are the first 20 blogs in terms of visitability according to the criteria and categorization of "Technorati" in May 18th, 2011:

1. The Huffington Post - http://www.huffingtonpost.com

2. Mashable! - http://mashable.com

3. TechCrunch - http://www.techcrunch.com

4. Engadget - http://www.engadget.com

5. The Daily Beast - http://www.thedailybeast.com

6. TMZ.com - http://www.tmz.com

7. Boing Boing - http://www.boingboing.net

8. Think Progress - http://thinkprogress.org

9. Business Insider - http://www.businessinsider.com

10. CNN Political Ticker - http://politicalticker.blogs.cnn.com 
11. WhiteHouse.gov Blog - http://www.whitehouse.gov/blog

12. Deadline.com - http://www.deadline.com

13. PlayStation.Blog - http://blog.us.playstation.com

14. Hot Air - http://hotair.com

15. BuzzFeed - http://www.buzzfeed.com

16. Mediaite - http://www.mediaite.com

17. Vulture - http://nymag.com/daily/entertainment

18. ReadWriteWeb - http://www.readwriteweb.com

19. Popeater - http://www.popeater.com

20. The Next Web - http://thenextweb.com

\section{RESULTS/COMMENTS}

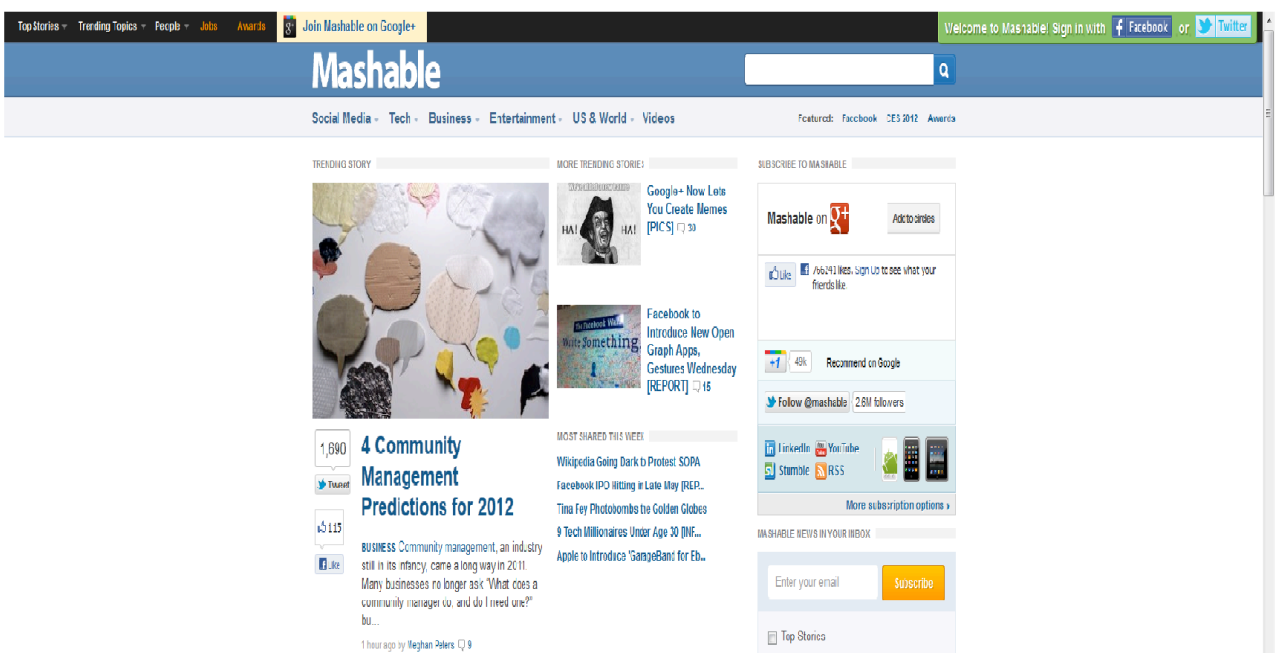

Figure 2. Mashable, heading and main part

\subsection{Paradicmatic Axis and Analysis}

Relating to the mechanisms of organization and reproduction of reality, for the 20 blogs studied, we detect the following:

A. In the headings, representations mainly concern the promotion of the blogs title which is usually highlighted by the application of the oppositional color axis (worm-cold), not only in the choice of the background but also in that of the fond. It is impressive that only 7 blogs use distinctive designs as a reinforcing element of the titles. The searching engine is an element closely related to the upper top of the blog, since its use directly concerns and signifies functionality, ease of use and effectiveness. Advertisements, paradoxically, are not a major part of the headings since only 9 out of 20 blogs have them there. It seems that the presentation of the blogs' content plays a more significant role and has a categorized, visible form, armored by the use of the oppositional axes in the dipole, verbal message-background together with the application of different fonts in variable shapes and sizes. Worth mentioning is the absence of text-image combinations to almost all blogs' headings. Whenever this happens is exclusively related to advertisements, signifying the clear commercial intent of the blog's constructors.

B. In the main part of the blogs, basic characteristic are the posts, combining images and texts. Most of them appear to be signed, have a diary writing form, include readability indicators, allow interactiveness with posting comments applications and have distinguishable frames. Moreover, the use of videos in posts is extensive while only in 5 cases on the main part of the blogs appear applications escaping the traditional form and including samples of advanced programming with the usage of animating and not static images (slides). Advertisements are an integral component of the blogs' main part and the 
one case that are absent is that of the governmental White House's blog. In many cases advertisements concern the blog itself (internal advertisement) and not external consumer's products. Typical is the case of the presentation and promotion of administrators and that of icons referring to social networks.

C. On the footer, very often, there are lists of links including articles of their categories. Their form is exclusively textual while they present elements of typology like the privacy policies and terms of use.

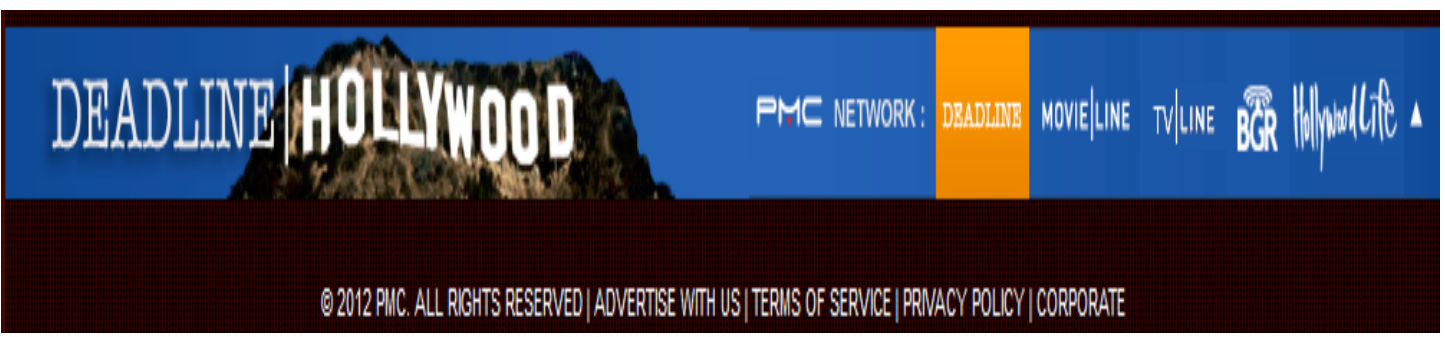

Figure 3. Deadline, footer

\subsection{Syntagmatic Axis and Analysis}

Relating to the production of meaning stemming from the discourse and the images of blogs, we observe the following:

The dairy writing form is the characteristic element of blogs' posts and signifies everydayness in contact and in use which is a basic end of the founders' ambitions.

Choosing the horizontal layout for the totality of the blog's headings, refers to the western societies' traditional typographic reading from the left to the right and in a stereotypical western-centered field, is an indicator of the blogs aimed public.

The color blue strengthens the emotional tranquility, serenity, pleasure and recuperation. Moreover it favors the ethical and honest addressing of survival issues while it expresses seriousness, responsibility, knowledge, trust, authority, and melancholia. Typical is the fact that the color blue is used in news blogs. The white color which is used by most blogs represents harmony and signifies simplicity, perfection, innocence, truth, youth, honesty, light, wisdom, sanctity, the spiritual authority and veracity.

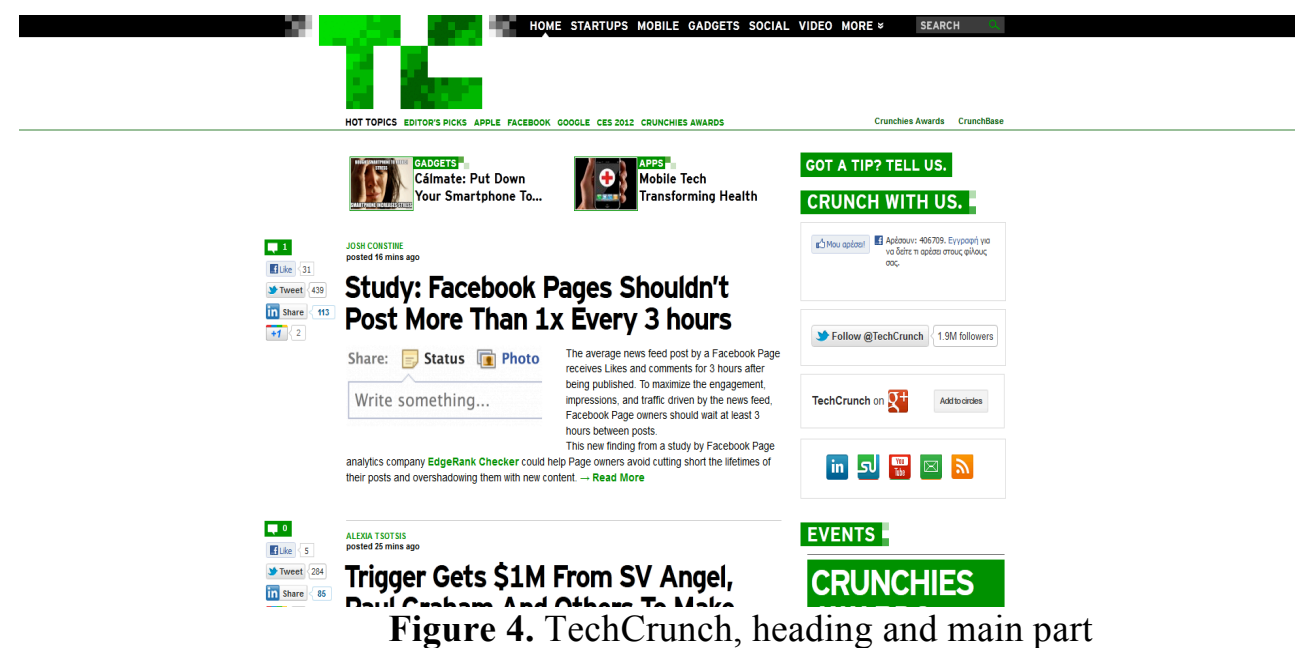

The color red considers being a color of action and is related to energy, vitality and sexuality, interest in life, happiness, spontaneity, excitement, danger, aggression, ambition, rebellion and love. In this study we find it mostly in blogs having social and commercial interest.

Color brown is related to diligence and intelligence while it signifies reliability and competence. It is found in only one blog of political content. The minimalist look, which is 
characteristic of the blogs' upper tops and footers, it is viewed as a central point of clarity and ease of navigation. The vertical layout for the main part of all the blocs conveys the concept substantiality.

The promotion of blogs' administrators in many cases comes with their picture signifying personal recognition. 10 out of 20 blogs have a repetition of the bar containing their logotype which seems to aim at their promotion and memorization on behalf of the readers. Concerning repeated characteristics and absences we found:

In 18 out 20 blogs there is not an indicator of time and date on the headings. Wherever this happens, the choice of font and color doesn't make its presents felt and visible. On the contrary dates do exist in all the posts

In most of the blogs there is not a connection between their title and their founders' names $(18 / 20)$. Social networks seem to be very important since are found in every blog except the on of the White House.

Typology seems to exist on the footers related to Copyright, privacy policy, terms of use, information related to the blog itself, and advertisements.

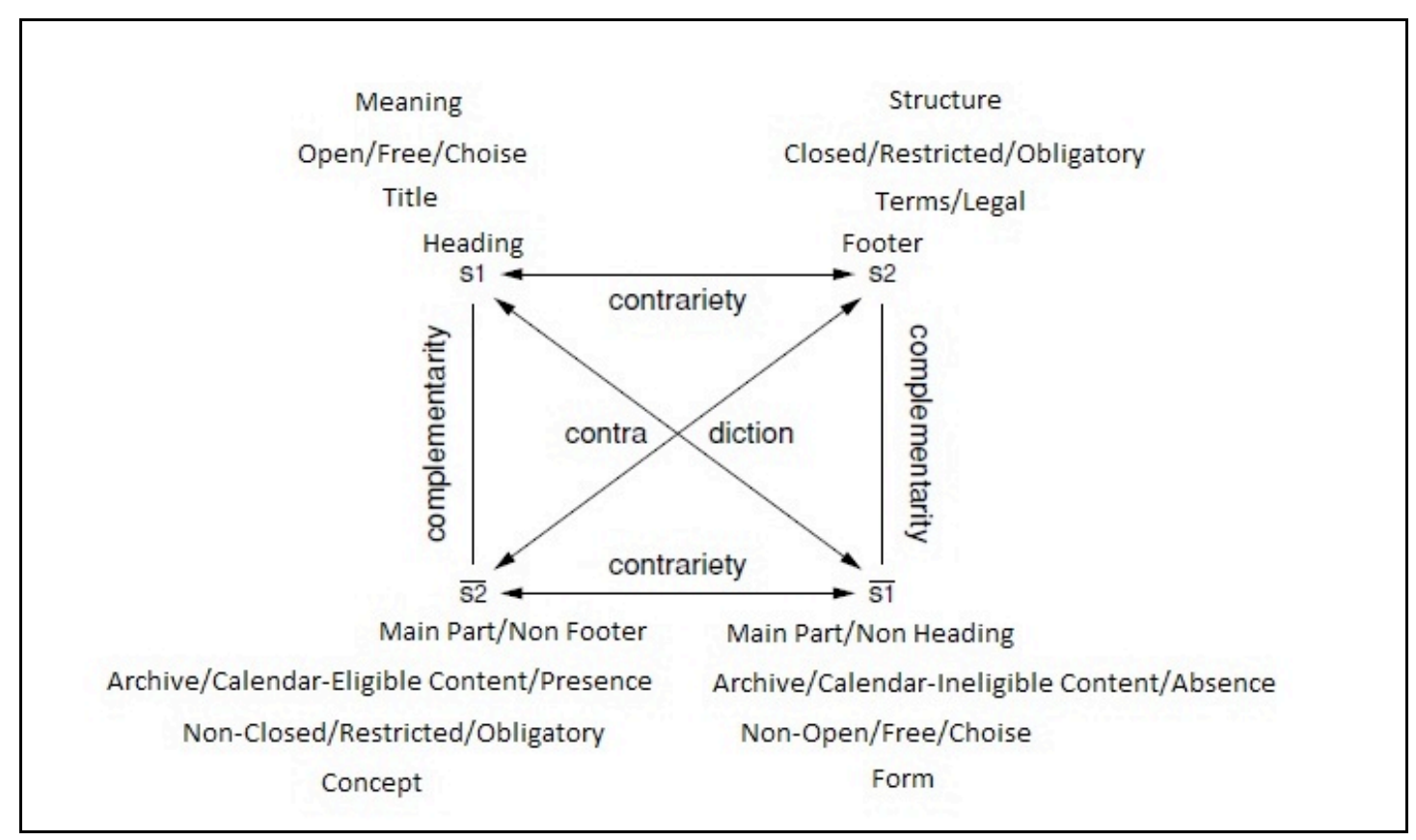

Figure 5. Greimas' square-Applied in blogs typology

Applying Greimas' square we can remarke that the meaning (messages) of the weblogs operates complementary to the concept (discource) with the structure (the mechanisms of organization and reconstruction) operating complementary to the form (signifiers and absences). Thus we can testify their effectiveness and their power for the receivers in the context of semiotic contemporary communication (Kress, 2010).

\section{REFERENCES}

Baldry, A. P. \& Thibault, P. J. (2006). Multimodal Transcription and Text. London: Equinox. Barthes, R. (1957). Mythologies. London: Paladin.

Barthes, R. (1964). Elements of Semiology. New York: Hill and Wang.

Blood, R. (2000). Weblogs: A History and Perspective, Rebecca's Pocket. Retrieved in March 22, 2011, from http://www.rebeccablood.net/essays/weblog history.html 
Blood, R. (2004). "How blogging software reshapes the online community", Communications of the ACM, Vol. 47(12), pp. 53-55.

Drezner D. W. \& Farrell H. (2008). Introduction: Blogs, politics and power: a special issue of Public Choice, Public Choice, Vol. 134, pp. 1-13.

Eco, U. (1997). The Search for the Perfect Language. Oxford: Blackwell Publishing.

Gillian, D. (1982). Advertisement as Communication. Athens: Patakis.

Greimas, A. J. (1984). Structural semantics: an attempt at a method. University of Nebraska Press: Lincoln.

Halliday, M.A.K. (1994). An introduction to functional grammar. [2nd Ed.]. London, Melbourne, Auckand: Edward Arnold.

Kress, G. (2010). Multimodality, a social semiotic approach to contemporary communication. New York: Routledge.

Kress, G.R., \& van Leeuwen, T. (1996). Reading Images: the grammar of graphic design. London: Routledge.

Lenhart, A. and Fox, S. (July 2006). Bloggers: a portrait of the internet's new storytellers. Pew Internet \& American Life Project, Retrieved 10/1/2012, http://www.pewinternet.org/ /media//Files/Reports/2006/PIP\%20Bloggers\%20Report\%20Jul y\%2019\%202006.pdf.pdf

Lenhart, A., Horrigan, J., and Fallows, D. (February 2004). Content creation online. Pew Internet \& American Life Project, Retrieved 10/1/2012, http://www.pewinternet.org/ /media//Files/Reports/2004/PIP_Content_Creation_Report.pdf.p $\underline{\mathrm{df}}$

Mead, R. (2000). You've Got Blog. The New Yorker, 13 November 2000.

Mishne, G. A. (2007). Applied Text Analytics for Blogs. Enschede: PrintPartners Ipskamp.

Sonesson, G. (2001). Iconicity strikes back: the third generation - or why Eco is still wrong. VISIO 9: 3-4, Retrieved 10/1/2012,

http://projekt.ht.lu.se/fileadmin/user_upload/project/ccs/Iconicity_strikes_backTx.pdf 